\title{
Preface
}

Thanks to Prof. Abd El-Fatah Abomohra, the Head of New Energy and Environmental Laboratory (NEEL), Dept. of Environmental Engineering, School of Architecture and Civil Engineering, Chengdu University, China, for assisting the Modern International Green Cultural Communication Association (MIGCCA) to successfully hold the 2021 International Conference on Environmental Engineering, Agricultural Pollution and Hydraulical Studies (EEAPHS 2021) during May 29-30, 2021 at Junyi Dynasty Hotel in Wuhan, China.

The global pandemic of Corona Virus Disease 2019 (COVID-19) has become a new infectious disease which spreads most widely, causes the most diseases and deaths to human beings, and causes the most serious social and economic losses in human history. The long road of epidemic prevention tests the soul and wisdom of human beings and calls for people to have a deeper understanding of environmental problems. The objective of EEAPHS 2021 is to provide a platform to analyze the interrelation between environmental engineering, agricultural pollution and hydraulical studies. It is expected to open the way to elimination of environmental pollution and ecological crisis as well as to protection of green environment for human existence.

By the influence of COVID-19, the EEAPHS 2021 brought together only 21 participants from 16 universities. The process mainly included opening ceremony, keynote speeches sessions, oral presentations sessions, summary and closing ceremony. We highly encouraged doctorate $(\mathrm{PhD})$ and postgraduate students to present their research proposal and findings. And Prof. Abd El-Fatah Abomohra's humorous speech made the atmosphere lively, and everyone who entered the meeting burst into applause. Everyone present judged the meeting a success.

In addition, the EEAPHS 2021 has received 51 manuscripts, 29 submissions have been accepted by the reviewers. All papers included into this collection have undergone careful peer-review by at least two reviewers before being selected for publication. The acceptance would be granted if the recommendations from the reviewers were positive. The criteria are based on the technical criteria, quality criteria, presentation criteria and format. Authors should make sure the submitted papers use the template for this conference.

We are particularly grateful to all of the authors and participants. Meanwhile, we would like to thank the committee members, the reviewers and everyone who worked for and participated in reviewing papers and making valuable suggestions for the improvement of the conference. Special thanks go to EDP Sciences for their sincere help and high efficiency in publishing and indexing for all articles. We look forward to the next EEAPHS conference.

\section{EEAPHS 2021 Organizing Committee}

May 31, 2021 